\title{
Transfusion and refusal: trials and tribulations
}

This article was published in the following Dove Press journal: International Journal of Clinical Transfusion Medicine

\author{
Olivier Garraud ${ }^{1,2}$ \\ Jean-Daniel Tissot ${ }^{3,4}$ \\ 'Faculty of Medicine, University \\ of Lyon, Saint-Etienne, France; \\ ${ }^{2}$ Institut National de la Transfusion \\ Sanguine, Paris, France; ${ }^{3}$ Transfusion \\ Interrégionale CRS, Epalinges, \\ Switzerland; ${ }^{4}$ Faculty of Biology and \\ Medicine, University of Lausanne, \\ Switzerland
}

\begin{abstract}
Transfusion is special, not only because it is a life-saving therapy from caring siblings and, more commonly, anonymous benevolent donors, but also because blood is nontrivial, symbolic, and carries ancestral fears. Blood is generally offered and should be accepted by the beneficiaries, meaning that the question should be addressed to them. Most often, the question is not whether they accept the donated blood, but whether they accept the minimal risk associated with it. This is a different matter, and it can be questioned whether both the questions are actually put to the respondent, that is, the patient needing the transfusion, to present better what transfusion is and what the benefit/risk ratio is. Since acceptance is an issue, refusal is the flipside. Some patients, including those with religious faiths (such as Jehovah's Witnesses), refuse blood transfusion; they also refuse bloodshed on the battlefield. It is a situation that represents a high medical and psychological burden for healthcare practitioners. Practitioners have, however, strived to respect the beliefs of Jehovah's Witnesses and have helped advance bloodless medical and surgical interventions that have benefited all those involved. This paper attempts to clarify some of the issues pertaining to blood refusal by groups of believers such as Jehovah's Witnesses and takes the opportunity to clarify certain blood acceptance issues with regard to its opposite, blood refusal, and decision-making process.
\end{abstract}

Keywords: transfusion, ethics, Jehovah's Witness, healthcare refusal

\section{The main driver in transfusion medicine: a no-other-option decision}

Transfusion saves lives in a number of clinical situations like trauma, surgery, delivery, and postpartum bleeding, whereas in others, it assists curative therapy, enabling patients to undergo intensive treatment such as chemotherapy, grafts or bone marrow transplantation. In other cases, transfusion supports patients presenting with chronic hematological disorders, either congenital (such as hemoglobinopathy) or acquired (aplastic anemia). After correction of hemoglobin levels, patients may benefit more than a "normal" life. In all cases, transfusion is indicated when no validated alternative is available and only if "Patient Blood Management" and "Optimal Use of Blood" programs (which are conceptually often merged) have explored all alternative approaches. It should be noted, however, that a low hemoglobin level and impaired hemostasis are not, per se, indications for transfusion, and everyone should be tested to avoid overexposing patients to blood components. ${ }^{1}$ The balance between over- and undertransfusion is a real challenge for many physicians in their routine practice. Nevertheless, in most medical environments, especially in high-income countries or
Correspondence: Olivier Garraud Institut National de la Transfusion Sanguine, 6 rue Alexandre-Cabanel, 75015 Paris, France Email ogarraud@ints.fr 
settings, the prescription of transfusion has become "a noother-medical-option decision" because any available alternatives have already been explored and implemented. This does not hold true everywhere, however, especially in low- or middle-income countries or settings where all too often transfusion is underprescribed due to an insufficient inventory. ${ }^{2} \mathrm{~A}$ major goal for "an almost all transfusion system" is having an ad hoc blood component inventory, meaning not a single patient in need of blood will die because the blood bank has run short of blood components. ${ }^{3}$ The specific situations of sensitive groups of patients with rare blood groups or multiple antibodies requiring special care are discussed in this paper.

\section{The central issue of patient information}

Apart from the vital emergencies, the complete details of blood transfusion should be explained to the recipient whenever possible; it is essential to inform the patient about the benefits and risks and to obtain their informed consent to the transfusion after all questions and queries have been appropriately answered and addressed. ${ }^{4}$ Consent must be requested from the parents of patients who are too young to give their own consent, if the country's regulations require it, while in some countries, child and teenage patients are considered capable of making decisions themselves, and such decisions are sovereign. Consent may also be requested from the family or relatives of elderly or mentally impaired persons, again depending on the applicable specific laws for the protection of vulnerable and/or mentally incapacitated patients. Special attention must be given to patients with sight and hearing loss, to ensure they have received and understood all relevant information. Last, a neglected issue relates to migrants and the difficulties encountered when individuals face language barriers in the host country. In all circumstances, communication and information are the cornerstones of a shared medical decision with shared informed consent. Information is generally requested to be provided orally rather than in the form of a leaflet, although leaflets are useful for providing follow-up information and reminders, as well as useful references like names, phone numbers, and email contacts. Appropriate, but honest, accurate and up-to-date information is an essential step in the transfusion process. It should neither minimize nor maximize the benefits and risks and allow the patients to make a decision that is in their best interests. ${ }^{5}$ Traceability of the information provided is mandatory as it is not trivial to trace oral communication; this has to be discussed within the policy and quality management system of the healthcare facility. Elements of proof are being increasingly requested in cases of legal issues.

\section{What makes transfusion so special?}

Agreeing to transfusion therapy is not a simple decision for a patient, for several reasons. First, the patient has to come to terms with the diagnosis of an illness, which is sometimes associated with a high burden, particularly in cases of chronic diseases such as organ (kidney, bone marrow) failure or cancer. The patient then has to cope with complex treatments such as chemotherapy, radiotherapy, or immunosuppression. ${ }^{6}$ Last, the possibility of a transfusion may awaken fears in patients, especially elderly people who can still recall the tainted blood scandals. And even if the patients are not specifically afraid of getting HIV or HCV through transfusion, they are presented with updated information on the residual risks of transfusion-transmitted infection. Actually, in high-income settings, the residual risk of getting infected by transfusion has become as low as $\sim 1$ in 4.5 million for HIV and HBV (data calculated by the French Ministry of Health, 2014-2016); it has dropped to one in 34 millions of components for HCV, and it has been annihilated for HTLV. Data obtained while having implemented systematic nuclear acid testing to test each donation in France have been revisited recently. ${ }^{7}$ Still, transfusion may remain frightening to some beneficiaries. Indeed, blood and blood components are in no way trivial; unlike chemicals, with active components and excipients, they are not manufactured drugs even though they are sometimes considered drugs. ${ }^{8}$ Blood components are not derived from the medical industry, but from another person's body, and have been given specifically for the purpose of being transfused to someone in need. Blood donors are people who are by nature healthy, a mandatory condition to the donation's consent. The gesture of donating blood is sharing good health with the sick; it is a transfer. The given blood has already bathed and nurtured another body - that of the donor - and this act of sharing brings in elements beyond the missing hemoglobin, iron, platelets, fibrinogen, or other clotting factors. ${ }^{9}$ It also brings material factors; even at trace levels (when the component is plasma poor), plasmarich components bring immunoglobulins that have reacted against foreign encounters experienced by the donor, and specific nutrients that characterize the blood diet or the use of toxins such as drugs, tobacco, or alcohol. This sharing also brings nonmaterial elements that are altruistic, humanistic, and secular values. The sharing may even bring spiritual values, either because this was the donor's intent or because 
the recipient feels this way. The logo "give blood, save lives" is promoted in many blood establishments and blood donor associations. Blood donation is sometimes considered as life-giving, an essential function with many consequences, including a responsibility toward the beneficiary, and due respect from the recipient to the donor, yet the principle of responsibility has been neglected by most ethicists involved in transfusion medicine. ${ }^{10} \mathrm{~A}$ (moral) debt may arise from blood donations. Interestingly, in the Voluntary Nonremunerated Blood Donation system, the donation is made to the society (the nongovernmental organization in charge of collecting blood, the blood establishment, or even the blood bank) which transfers it to the recipient; ${ }^{11}$ this represents the second aspect of transfers (the first being good health and well-being). This third-party organization removes the debt and ensures the anonymity and altruism of the donor. ${ }^{12}$

\section{Why do people refuse transfusion?}

Although transfusion should never be superfluous and should be prescribed on very serious medical grounds, healthcare providers occasionally face blood transfusion refusal. The most common type of blood transfusion refusal is associated with a patient's decision to no longer undergo active treatment and accept only palliative care. ${ }^{13}$ This case is normally agreed between the patients and their family and the medical staff in charge. Some countries have passed a law allowing advance formal approval of a patient's wish not to endure intensive care, as is the case in France, although in other countries, hearsay may be sufficient for the consideration of the medical staff. In some situations, however, for philosophical reasons, some people may refuse to endure long-term and difficult treatment when they foresee little benefit in terms of life expectancy or quality of life, whether they are right or not with respect to these parameters or indicators. In the latter case, active therapy should be considered by the treating physicians as the patient remains curable; however, they do not want to prolong life, and transfusion is perceived as an active therapy which is no longer wished. These cases are serious and difficult to manage for dedicated medical staff, especially in low-to-middle-income countries, and it may be almost unbearable when the patient is a child. ${ }^{14}$ In most low-to-middle-income countries, the child's words may not be accepted and the law requires parental confirmation. In English-speaking, German-speaking, and Nordic countries, children's opposition to care and cure has occasionally been accepted by the legal authorities. Last, a number of patients oppose blood transfusion and all forms of blood absorption on religious grounds, and several Christian sects, including the well-known Jehovah's Witnesses, defy hematology and emergency wards in their refusal of blood.

\section{Religious beliefs and blood}

The spiritual essence of blood has been depicted or detailed in many academic texts, ${ }^{15}$ and this study will not attempt to cover this very broad topic. Some salient points do deserve to be highlighted, however, to help us understand the fears and prohibitions associated with blood: 1) blood is associated with life in almost every civilization and is, or at least a substitute or equivalent of it is, often associated with the creation of life on earth, at the origin of many cosmogonies; 2) blood is not uniform, and it is depicted in at least two lights, a bright one that glows and flows under pressure from arteries, and a dark one commonly associated with suffocation, menses, and poured from veins; 3) blood nourishes Gods, and either calls for favors or wards off disasters; 4) blood from enemies must be visible (outside cities, however) and must be shed abundantly. Heroes' blood is greatly valued, however; 5) blood, as a symbol, such as animal sacrifice, either calls for God's justice or protects the righteous (very much valued among Semitic people, Hebrews, Jews, and later Muslims); 6) blood must never be mixed, nor absorbed in food or beverages, hence Kosher and Halal rites; 7) in contrast to the very many prohibitions associated with it, blood can call for transgression, as in black magic and syncretic rites exemplified by Afro-American rites, including voodoo. Christians have endeavored to build a theology about the blood of Jesus Christ, an instrument of salvation. Saint John in Revelation writes "[They] washed their robes and made them white in the blood of the Lamb," where - according to theologians - Christ's (the Lamb's) blood has the power to erase people's sins (tainted robes). Whereas Protestants revere the Eucharistic sacrifice as a commemoration, a symbol, the Catholics believe in Christ's genuine presence in the bread and wine, representing His actual body and actual blood. ${ }^{16}$ These brief points should each be developed as they are merely snapshots, but they attempt to provide evidence that blood is at least nontrivial and at most extraordinary.

\section{The Jehovah's Witnesses' faith and consideration of blood}

Jehovah's Witnesses are millenarian Christians, sharing little with other reform-inspired churches, and one of their most well-known characteristics is their refusal of the Holy Cross. Jehovah's Witnesses read the Bible (comprising the majority of Old and New Testament books common to all Christians, with some deletions and a few additions) literally and not 
interpretatively. Many verses in both the Testaments which state that blood is life and should neither be spilled in vain nor be absorbed in contact, foods, or beverages represent an absolute guide. Jehovah's Witnesses also refuse bloodshed on the battlefield and usually refuse to join the army or serve in active battalions. Jehovah's Witnesses believe that a definite number of righteous people are predetermined for eternal life, through all generations since Creation. Everyone else will be eternally damned. This is a small number $(144,000)$, and each capital sin compromises eternal life for good, as unlike other Christians, Jehovah's Witnesses do not believe in redemption. Because the prohibition is absolute in various verses of the Bible, the absorption of blood represents a capital sin and sends the sinner to hell, with no chance of ever being rescued after the "Last Day" battle, Armageddon. ${ }^{17}$

\section{Understanding the refusal of blood transfusion from the Jehovah's Witnesses' standpoint}

The Jehovah's Witnesses emerged at the end of the 20th century, at a time when transfusion was pioneered. As transfusion became established, Jehovah's Witnesses had to build a theory, which they did, with textbooks and leaflets, and much later webpages. Jehovah's Witnesses are very well organized, and each worshiper has a role in the community. Worthy of note is that a few years ago (last accessed in 2010 or so in their website), after having explained that the Bible bans blood absorption in all forms, they concluded that blood transfusion should be banned because blood can carry infections, which makes this medical practice a highly risky one. This argument was not untrue, but the figures provided as examples dated back decades just after the disastrous tainted blood scandal (around 1990-1995). Interestingly, for part of society, the HIV epidemic represented the price paid for liberal sex, when sex was not intended to promote human reproduction, as sex stopped being associated with the gift of life, it began to give death. ${ }^{18}$ Inaccurate information on the infectious risks of transfusion was in absolute contradiction with the ethical and moral duty to provide up-to-date, state-of-the-art information on both the benefits and risks. Indeed, their presentation of transfusion-transmitted infections was multiplied 10,000- to 100,000-fold compared with the actual situation at the time, when the case was few years back. Recently, the Jehovah's Witness' official website (accessed in March 2018) stated that the ban on blood is not based on medical but on religious considerations only, a matter of faith. Of interesting note, besides the reported risks of infection, Jehovah's Witnesses used to cite also complications of transfusion to argue against transfusion (such as transfusion-related acute lung injury and transfusion-associated circulatory overload); they now prefer setting their argument on religious grounds only. It must be understood that Jehovah's Witnesses are religious people who believe absolutely and literally that their eternal life will be compromised after sinning. Life is short and represents a pilgrimage on earth with limited importance, while eternity is for good. It is very unwise for medical officers or nursing staff to debate theology, whereas compassion and extending kindness offer greater opportunities for opening up a window on acceptance of blood transfusion for both themselves and their beloved relatives, especially children. However, this window might be very small because loving parents desire eternal life for their children. Plasma and plasma derivatives (plasma-derived drugs) are not regarded as blood and are therefore not banned, nor are transplants. ${ }^{19}$ Jehovah's Witnesses are also inconsistent regarding another medical intervention: vaccination; they used to refuse all vaccination, but now say it is acceptable (which does not correspond to complete compliance with mandatory vaccination programs). Vaccinations are obviously not forbidden in the Bible because they are a product of modern science and medicine, but it could be argued that transfusion - a contemporary of vaccination - also results from modern medicine and is not specifically forbidden as a medicine in the Bible, unlike other forms of blood absorption. This argument has little chance of success, but it is worth trying. Experience also teaches that some worshippers are eager to be convinced by strong arguments, especially when life becomes an issue when dying at a young age or when seeing a child dying.

The Jehovah's Witness blood transfusion refusal issue is highly difficult to handle for, or to cope up with, the concerned medical staff, especially in low-to-middle-income countries. There again, country laws differ concerning whether the patient's expressed will is respected or disregarded, although the increasing consideration of patients' rights has altered attitudes toward refusal, especially when the patient is an adult. There are nevertheless two difficult cases to solve: 1) how to manage a teenager's refusal of blood: Jehovah's Witnesses are considered as adults after the Confirmation sacrament, generally received by the age of 16 years, while most common law considers adulthood to be from age 18 years and 2) how to manage the case of mentally impaired persons, either elderly or disabled, when their family or parents pretend their relative was a true Jehovah's Witness worshipper. In the latter case, clear and advance expression of willingness, which is a legal requirement in certain countries, clarifies how this difficulty is handled. Medical staff 
and administrations should, however, be prepared for law suits, since Jehovah's Witnesses can raise a highly effective network of observers in all hospitals to report on suspected (or genuine) malpractice. Records should be crystal clear regarding all due information processes, performed in the presence of a legal witness whenever possible.

Not to be underestimated, however, is the fact that some progress has been made by the transfusion community, under the influence of the Jehovah's Witnesses community. Indeed, bloodless surgery programs have been sought after and are now a part of Patient Blood Management programs (which are largely promoted by the Jehovah's Witness Consistory). ${ }^{20,21}$ Some clinics even rule "deserytrocytation" of stem cell transplants. Regarding this issue, several trials have been reported, which although limited in size present valuable data. ${ }^{22-25}$ Furthermore, many programs have revised cut-off for prescribing transfusion, based upon recommendations made by scientific societies and regulatory bodies, and meta-analyses of clinical trials. Nonetheless, it may happen that bloodless resuscitation does not suffice; in a recent survey, an Australian group have reported that 34 members of Jehovah's Witnesses suffering from major trauma bleeding, in which 3 had to undergo transfusion. ${ }^{26}$ The cooperation of patients is sought more nowadays than in the past and alternatives to transfusion are discussed. Preoperative control of anemia has become the rule in many settings and is expanding fast in healthcare centers. Blood saving techniques used pre and post-surgery have also been deployed in many operating rooms. The main issue - and by extension the main case to be discussed or for making decisions - relates to acute or massive loss of blood, requiring urgent action and sometimes transfusion, even though drugs (tranexamic acid) or biologicals (factor VIIa, fibrinogen, cryoprecipitate, etc) can be used to control the bleeding.

\section{Conclusion}

One of the major improvement achieved during the recent past in the field of transfusion medicine is the involvement of patients or relatives in the decision-making relative to the prescription of blood components, or alternatives to transfusion, or both. Relevant information procurement and seeking for consent are seminal in the ethical process of transfusion medicine.

The case of blood transfusion refusal by religious groups such as Jehovah's Witnesses has long been very challenging for medical communities in Latin American countries, unused to the act of deliberately choosing death. Although healthcare practitioners may perceive it as a failure of proper patient management, it should illustrate the value of the blood and serve as a reminder that it is certainly not trivial (or clerical). ${ }^{26}$
The commodification of blood and blood products should also be regarded as a failure to respect patients' feelings and perceptions that go beyond the materiality of blood. Moreover, the majority of blood transfusion refusal cases relate to patients who expect no quality from a prolonged life and deny any benefit in having a few extra weeks (or months) of life. Evaluating the risks and benefits of transfusion in cases such as this may become a challenge. The consideration that the blood component inventory is then spared - as is sometimes heard from a category of highly responsible patients refusing prolonged care - should not be a decisive factor, according to the principle of justice and equity in care provision. Responsible blood component inventory management must encourage Patient Blood Management, but should not integrate patient's self-restrictions on being transfused. All such cases profoundly challenge healthcare providers and should be addressed in support groups considering all ethical issues that arise in the blood transfusion process. Last, the issue of blood refusal exemplifies the common acceptance of blood transfusion. Indeed, the information provided to and the informed consent given by patients prior to transfusion emphasize the acceptance of donated blood and the gift itself; the other side of the coin is refusal, and both acceptance and refusal exist because the opposite exists. This issue seems to be largely ignored while it should perhaps be kept in mind.

\section{Disclosures}

The authors report no conflicts of interest in this work.

\section{References}

1. Voorn VMA, van Bodegom-Vos L, So-Osman C. Towards a systematic approach for (de)implementation of patient blood management strategies._Transfus Med. 2018;28:158-167.

2. Katz LM, Donnelly JJ, Gresens CJ, et al. Report of a workshop on ensuring sustainable access to safe blood in developing countries: International Blood Safety Forum, March 24, 2017. Transfusion. 2018;58:1299-1306.

3. Osorio AF, Brailsford SC, Smith HK. A structured review of quantitative models in the blood supply chain: a taxonomic framework for decisionmaking. Int J Prod Res. 2015;53:7191-7212.

4. Shander A, Gross I, Hill S, Javiddroozi M, SLedge S. A new perspective on best transfusion practices. Blood Transfus. 2013;11:193-202.

5. Squires JE. Risks of transfusion. Southern Med J. 2011;104:762-769.

6. Waller A, Forshaw K, Bryant J, Mair S. Interventions for preparing patients for chemotherapy and radiotherapy: a systematic review. Support Care Cancer. 2014;22:2297-2308.

7. Laperche S, Tiberghien P, Roche-Longin C, Pillonel J. Fifteen years of nuclear acid testing in France: results and lessons. Transfus Clin Biol. 2017;24:182-188.

8. Brophy A, Opsha Y, Cardinale M. Blood, blood components, plasma, and plasma products. Side Effects Drugs Annual. 2016;38:335-353.

9. Garraud O, Tissot JD. Theoretical and experimental ethics: advocacy for blood donors and beneficiaries of blood transfusions. Transfus Med. 2017 Epub Sep 5.

10. Garraud O, Lefrère JJ. Voluntary non-remunerated blood donation and reasons for donating: is there room for philosophy? Blood Transfus. 2014;12(Suppl 1): s404-s405. 
11. Tissot JD, Lion N. Myths: history, blood, sex and money. Blood Transfus. 2013;11:1-3.

12. Allain JP. Moving on from voluntary non-remunerated donors: who is the best blood donor? Br J Haematol. 2011;154:763-769.

13. Cain CL, Surbone A, Elk R, Kagawa-Singer M. Culture and palliative care: preferences, communication, meaning, and mutual decision making.J Pain Symptom Manage. 2018;55:1408-1419.

14. Snaman JM, Kaye EC, Baker JN, Wolfe J. Pediatric palliative oncology: the state of the science and art of caring for children with cancer. Curr Opin Pediatr. 2018;30:40-48.

15. Garraud $\mathrm{O}$, Lefrère JJ. Blood and blood-associated symbols beyond medicine and transfusion: far more complex than first appears. Blood Transfus. 2014;12:14-21.

16. Biale D. Blood and Belief: The Circulation of a Symbol Between Jews and Christians. Berkeley, CA, USA: The University of California Press; 2007:316 pp.

17. Chryssides GD. Jehovah's Witnesses: Continuity and Change. London: Routledge; 2016:320 pp.

18. Parker RG, Herdt G, Carballo M. Sexual culture, HIV transmission, and AIDS research. J Sex Res. 1991;28:77-98.

19. Doyle DJ. Jehovah's Witnesses and artificial blood. CMAJ. 2000;163: 495-496.

20. Reyes Garcia A, Vega González G, Andino Ruiz R. Short-term outcome of cardiac surgery under cardiopulmonary bypass in patients who refuse transfusion: a controlled study. J Cardiovasc Surg (Torino). 2018 Epub Apr 3.
21. Olaussen A, Bade-Boon J, Fitzgerald MC, Mitra B. Management of injured patients who were Jehovah's Witnesses, where blood transfusion may not be an option: a retrospective review. Vox Sang. 2018;113: 283-289.

22. George JN, Sandler SA, Stankiewicz J. Management of thrombotic thrombocytopenic purpura without plasma exchange: the Jehovah's Witness experience. Blood Adv._2017;1:2161-2165.

23. Valle FH, Pivatto F Júnior, Gomes BS, Freitas TM, Giaretta V, Gus M. Cardiac surgery in Jehovah's Witness patients: experience of a Brazilian tertiary hospital. Braz J Cardiovasc Surg. 2017;32: 372-377.

24. Hardesty DA, Doerfler S, Sandhu S, et al. Bloodless neurosurgery among Jehovah's Witnesses: a comparison with matched concurrent controls. World Neurosurg. 2017;97:132-139.

25. Sheth M, Kulkarni S, Dhanireddy K, Perez A, Selby R. Blood conservation strategies and liver transplantation transfusion-free techniques derived from Jehovah's Witness Surgical Cohorts. Mo Med. 2015;112:389-392.

26. Olaussen A, Bade-Boon J, Fitzgerald MC, Mitra B. Management of injured patients who were Jehovah's Wittnesess, where blood transfusion may not be an option: a retrospective review. Vox Sang. 2018;113:283-289.

26. Garraud O. Jehovah's Witnesses and blood transfusion refusal: what next? Blood Transfus. 2014;12(Suppl 1): s402-s403.
International Journal of Clinical Transfusion Medicine

\section{Publish your work in this journal}

International Journal of Clinical Transfusion Medicine is an international, peer-reviewed, open access, online journal publishing clinicalexperimental, policy-making and evidence-based practices of all topics pertaining to clinical transfusion medicine. Original research, short reports, reviews, case reports and commentaries are invited.

\section{Dovepress}

The manuscript management system is completely online and includes a very quick and fair peer-review system, which is all easy to use. Visit http://www.dovepress.com/testimonials.php to read real quotes from published authors.

Submit your manuscript here: https://www.dovepress.com/international-journal-of-clinical-transfusion-medicine-journal 